\title{
СОЦИОЛОГИЯ
}

И СОЦИАЛЬНЫЕ ТЕХНОЛОГИИ

DOI: https://doi.org/10.15688/lp.jvolsu.2018.3.5

UDC 316.4.06

LBC 60.59

\section{THE IMAGE OF THE SOCIAL FUTURE OF THE YOUNG PEOPLE IN INDUSTRIAL REGION (IN THE CONTEXT OF THE VOLGOGRAD AND SVERDLOVSK REGIONS) ${ }^{1}$}

\author{
Yana V. Didkovskaya \\ Ural Federal University, Ekaterinburg, Russian Federation \\ Nadezda V. Dulina \\ Volgograd State University, Volgograd, Russian Federation \\ Dmitriy V. Trynov \\ Ural Federal University, Ekaterinburg, Russian Federation
}

\begin{abstract}
The article analyzes the results of the study of the image of the social future of young people considered by the authors as a set of social expectations, ideals and ideas of the younger generation about the prospects of society as a whole and their own opportunities to be realized in it.

The conclusions of the article are based on the results of a sociological survey of young people implemented by the authors in the period from May to August 2018 at the enterprises of two major industrial regions of Russia the Volgograd and Sverdlovsk regions. More than 600 young employees of industrial enterprises (aged not older than 30 years) of high-tech sectors of the economy - engineering, rocket science, aircraft engineering, metallurgy $\infty$ industry and IT were interviewed by the survey method on the Google Form platform.

ㄱ. A comparative analysis of the estimates of young people in these regions showed general trends in the $\infty$ formation of the image of the social future, typical for both regions, as well as regional features.

T. The authors state that a significant part of young people in the studied regions, rather negatively \% assess the current situation in various social spheres and adheres to pessimistic attitudes about the possible social future.

The study reveals that the youth of the Sverdlovsk region in comparison with the Volgograd youth critically assess the likely social future. Besides, divergence of expectations of the Sverdlovsk youth with its public ideal is recorded. The young people of the Volgograd region with a rather negative assessment of the situation, almost as critical as the youth of the Sverdlovsk region, expect favorable changes to a greater extent in the near future.

Summarizing the results of the study the authors focus on the imbalance between the social ideal and social expectations of young people in industrial regions as a dangerous trend fraught with increased radicalism and protest moods among young people. being.

Key words: image of social future, social expectations, young people, industrial region, social well-
\end{abstract}


УДК 316.4 .06

ББК 60.59

\title{
ОБРАЗ СОЦИАЛЬНОГО БУДУЩЕГО МОЛОДЕЖИ ИНДУСТРИАЛЬНОГО РЕГИОНА (НА ПРИМЕРЕ ВОЛГОГРАДСКОЙ И СВЕРДЛОВСКОЙ ОБЛАСТЕЙ) ${ }^{1}$
}

\author{
Яна Викторовна Дидковская \\ Уральский федеральный университет, г. Екатеринбург, Российская Федерация \\ Надежда Васильевна Дулина \\ Волгоградский государственный университета, г. Волгоград, Российская Федерация \\ Дмитрий Валерьевич Трынов \\ Уральский федеральный университет, г. Екатеринбург, Российская Федерация
}

\begin{abstract}
Аннотация. В статье анализируются результаты исследования образа социального будущего молодежи, рассматриваемого авторами как комплекс социальных ожиданий, идеалов и представлений молодого поколения о перспективах общества в целом и собственных возможностях реализоваться в нем.

Выводы статьи базируются на результатах социологического опроса молодежи, реализованного авторами в период с мая по август 2018 г. на предприятиях двух крупных индустриальных регионов России Волгоградской и Свердловской областей. Методом анкетирования на платформе Google Form было опрошено более 600 молодых работников промышленных предприятий (возраст - не старше 30 лет) высокотехнологичных отраслей экономики - машиностроения, ракетостроения, авиастроения, металлургии и сферы IT.

Сравнительный анализ оценок молодежи данных регионов показал общие тенденции в формировании образа социального будущего, характерные для обоих регионов, а также региональные особенности.

Установлено, что существенная часть молодых людей исследуемых регионов скорее негативно оценивает текущее состояние дел в различных общественных сферах и придерживается пессимистических установок относительно возможного социального будущего.

Выявлено, что свердловская молодежь оценивает вероятное социальное будущее критичнее, чем волгоградская, зафиксировано расхождение ее ожиданий с общественным идеалом. Молодые люди Волгоградской области при практически такой же негативной оценке ситуации в большей степени ожидают благоприятных изменений в ближайшем будущем.

Резюмируя результаты исследования, авторы заостряют внимание на дисбалансе между общественным идеалом и социальными ожиданиями молодежи индустриальных регионов как опасной тенденции, чреватой активизацией радикализма и протестных настроений среди молодежи.

Ключевые слова: образ социального будущего, социальные ожидания, молодежь, индустриальный регион, социальное самочувствие.
\end{abstract}

Введение. Современное общество стоит перед рядом экономических, политических и социальных вызовов. Для России основной из них сегодня - инновационный, что означает способность к модернизации, переходу от общества сырьевой экономики к конкурентоспособному обществу, базирующемуся на использовании IT, на развитии фундаментальной науки и образования, на эффективном использовании человеческого капитала. Безусловно, наиболее перспективным ресурсом, позволяющим осуществить такой переход, является российская молодежь. Однако в условиях экономического и технологического кризисов она подвержена многочисленным рискам, что ставит под угрозу возможность сформировать, а затем и реализовать свой потенциал. Среди таких рисков прежде всего значимы снижение образовательного ресурса молодежи, угроза ее депрофессионализации и невостребованности на рынке труда, отсутствие возможности для ее самореализации, риск потери социальной и групповой идентичности, политическая инфантильность и пассивность, сни- 
жение социальной активности. При этом динамизм современного общества предоставляет определенные перспективы и возможности, «жизненные шансы» для молодежи - социальные, культурные, технологические, самореализационные. Эти риски и возможности отражаются в комплексном феномене - образе социального будущего молодежи, составляющем предмет нашего исследования.

Исследовательский интерес и обращение к проблеме конструирования образа будущего на настоящем этапе объясняется высоким темпом социальных изменений в различных областях общественной практики, нарастанием количества ранее не возникавших, неопределенных социальных ситуаций, то есть новой социальной реальностью, которая сегодня определяется как социальная нестабильность и предъявляет повышенные требования к субъекту в плане активности.

В мировой социальной и психологической науке в основном исследуются проблемы социальных ожиданий в контексте процессов взросления и адаптации молодежи. Анализируются социально-экономические и психологические факторы социализации и связанные с ними многочисленные показатели благосостояния [9]. В англоязычных источниках используются такие понятия, как «ожидаемое будущее» или «воображаемое будущее», которые отражают социально-психологические характеристики жизнедеятельности молодежи. Поднимается следующий круг исследовательских вопросов: «Что определяет выбор молодым человеком места работы? Каковы причины миграции или творческой активности?» Эти вопросы ставятся в контексте проблем выбора молодежью жизненного пути, образования, места работы [10]. Особо подчеркивается проблема завышенных ожиданий, «необоснованных амбиций» [8] и их последствий, выраженных в девиантном и делинквентном поведении молодежи [7].

В российской научной литературе феномен образа будущего, факторы его формирования и функционирования изучены мало, однако в ряде социологических и психологических источников можно встретить обращение к этому понятию, которое связывается с весьма широким кругом тем. В проблемное поле образа будущего попадают такие вопросы, как самоопределение различных социальных групп, когнитивное конструирование будущего личностью, активное отношение к нему, социальные ожидания и жизненные стратегии молодежи [2; 3].

Анализ как зарубежной, так и отечественной научной литературы, показывает, что изучаются скорее представления индивидов о своих будущих, вероятных (ожидаемых) индивидуальных траекториях в социуме, нежели интегрированный образ этого социума, сложившийся у поколения или социальной общности. В нашем исследовании мы фокусируем внимание именно на последнем понимании данной категории и рассматриваем образ социального будущего молодежи как комплекс социальных ожиданий, идеалов и представлений молодого поколения о перспективах общества в целом и собственных возможностях реализоваться в нем.

Данные и метод. В качестве пространства исследования выступили индустриальные регионы, поскольку для них большое значение должно иметь развитие квалифицированного, творческого потенциала и воспроизводства кадров на крупных промышленных предприятиях.

Выбранные нами для сравнения российские регионы - Волгоградская и Свердловская области - относятся к традиционно индустриальным регионам, пережившим драматический процесс деиндустриализации. Деиндустриализацию российских регионов 1990-х гг. (и продолжающуюся отчасти до сих пор) связывают с промышленным спадом, сокращением доли промышленного производства в ВРП, возрастанием в нем удельного веса сферы услуг. С.Д. Бодрунов обращает внимание на то, что «деиндустриализация вызывает значительные негативные последствия и в социальной сфере: упрощение труда и используемых технологий, снижение наукоемкости и “знаниеемкости” производства, разрушение производственных коллективов и трудового образа жизни» [1, с. 22].

Однако в настоящее время социальноэкономическая ситуация в этих регионах несколько различна. Как отмечают социологи и экономисты, Волгоградская область остается на этапе первичной модернизации, основу экономики области составляют крупные 
промышленные предприятия, основанные в советское время, но безнадежно устаревшие, многие из них, например, бывший металлургический завод-гигант «Красный Октябрь», на грани банкротства [4]. Свердловская область хотя и пережила развал крупной промышленности, но за счет привлечения в регион бизнеса и развития сферы услуг сегодня демонстрирует достаточно успешную стратегию социально-экономического развития. Область достаточно быстро вошла в фазу развития вторичной модернизации и, как отмечает Г.Ф. Ромашкина, отличается высоким уровнем интеллектуального потенциала, политической и гражданской активности населения [5, с. 25].

Таким образом, объективные условия самореализации молодежи в исследуемых регионах определяются, с одной стороны, сходными последствиями процесса деиндустриализации, но, с другой стороны, имеется определенная специфика, связанная с различными этапами модернизации, на которых находятся Волгоградская и Свердловская области. Эти моменты во многом определяют контекст, в котором фиксируются различия в оценке молодежью актуального состояния общества и его возможных перспектив.

Выводы статьи базируются на результатах социологического опроса молодежи, реализованного авторами в период с мая по август 2018 г. на предприятиях Волгоградской и Свердловской областей. Методом анкетирования на платформе Google Form было опрошено более 600 молодых работников промышленных предприятий (возраст - не старше 30 лет) высокотехнологичных отраслей экономики - машиностроения, ракетостроения, авиастроения, металлургии и сферы IT.

\section{Результаты исследования}

Согласно полученным результатам исследования текущее состояние дел в различных общественных сферах (политике, экономике, социальной сфере и в культурной жизни общества) оценивается примерно одинаково в обоих регионах, к сожалению, в основном, на «двоечку» или «слабую тройку» (табл. 1).

Хуже всего оценивается состояние дел в экономике: на 2,23 балла среди молодежи Свердловской области и почти также низко - 2,33 балла - среди молодежи Волгоградской области. Кроме того, негативно оценивается социальная сфера, особенно свердловчанами. Немного лучше молодежь оценивает состояние дел в политике и культурной жизни общества. Обращает на себя внимание, что ни по одной из сфер общественной жизни средние оценки не достигают даже 3-х баллов.

Сравнивая средние оценки молодежи по Волгоградской и Свердловской областям, можно заметить, что, хотя резких различий не наблюдается, тем не менее критический настрой свердловской молодежи выражен несколько сильнее, за исключением оценок культурной жизни общества. Полученные результаты согласуются с данными других исследований социального самочувствия молодежи. Так, Екатеринбургские социологи отмечают, что негативные настроения уральской молодежи по сравнению с молодежью других регионов связаны с ее общим критическим настроем относительно настоящего и будущего, что традиционно проявляется в негативных оценках политической, экономической и социальной ситуаций [6].

Таблица 1

Оценка молодежью состояния дел в стране в различных сферах общественной жизни (5 баллов - дела идут в совершенно правильном направлении, 1 балл - дела идут в совершенно неправильном направлении), средние баллы

\begin{tabular}{|l|r|c|}
\hline \multirow{2}{*}{$\begin{array}{c}\text { Оцените, насколько дела в стране идут в правильном } \\
\text { или неправильном направлении в перечисленных ниже сферах: }\end{array}$} & $\begin{array}{c}|c| \\
\text { Регион } \\
\text { область }\end{array}$ & $\begin{array}{c}\text { Волгоградская } \\
\text { область }\end{array}$ \\
\hline В экономике & 2,23 & 2,33 \\
\hline В политике & 2,57 & 2,66 \\
\hline В социальной сфере & 2,37 & 2,43 \\
\hline В культурной жизни общества & 2,98 & 2,72 \\
\hline
\end{tabular}


Интересно, что если перейти от макроуровня социального самочувствия молодежи, измеряемого нами как удовлетворенность состоянием дел в различных сферах общества, к характеристике удовлетворенности своими индивидуальными, личными траекториями в этом обществе, то есть к оценке социального самочувствия на микроуровне, то мы можем увидеть другие различия в мнениях молодежи данных регионов (табл. 2). Молодежь Свердловской области свои возможности оценила несколько выше, чем волгоградская молодежь свои. Более благоприятное социально-экономическое развитие региона отражается наглядно на социальном самочувствии молодых работников. Особенно это прослеживается при переходе от оценки абстрактного «положения дел в стране» к оценке конкретных аспектов своей жизни в социуме.

Практически все параметры удовлетворенности жизнью у свердловской молодежи несколько выше, чем у волгоградской. Свердловчане более довольны своими работой и образованием, состоянием здоровья, отношениями с близкими и друзьями, с коллегами. Удовлетворенность своим мате- риальным положением - единственный параметр, который выше у молодежи Волгоградской области. Это, возможно, объясняется не столько объективными различиями в уровне жизни в данных регионах (анализ социально-экономических условий, приведенный нами в предыдущем разделе, показывает, что, напротив, в Свердловской области у молодежи и населения в целом скорее больше возможностей поддерживать свой экономический статус), сколько связано, на наш взгляд, с более высокими социально-экономическими запросами свердловской молодежи.

При этом перспективы изменения ситуации в обществе молодежь Волгоградской области оценивает более позитивно (табл. 3). Около $28 \%$ опрошенных волгоградцев полагают, что ситуация в обществе в ближайшее время изменится в лучшую сторону, тогда как среди молодежи Свердловской области таких оптимистов только 18 \%. Более половины молодежи Свердловской области и почти половина волгоградской молодежи занимает, казалось бы, нейтральную позицию, считая, что в ближайшее время ничего не изменится. Однако, учиты-

Таблица 2

Удовлетворенность молодежи различными аспектами своей жизни (1 балл - совершенно не удовлетворен, 5 баллов - полностью удовлетворен), средние баллы

\begin{tabular}{|l|c|c|}
\hline \multirow{2}{*}{$\begin{array}{c}\text { Оцените, насколько Вы удовлетворены или не удовлетворены } \\
\text { следующими аспектами Вашей жизни: }\end{array}$} & \multicolumn{2}{|c|}{ Регион } \\
\cline { 2 - 3 } & $\begin{array}{c}\text { Свердловская } \\
\text { область }\end{array}$ & $\begin{array}{c}\text { Волгоградская } \\
\text { область }\end{array}$ \\
\hline Состоянием здоровья & 3,75 & 3,63 \\
\hline Своей работой & 3,62 & 3,33 \\
\hline Своим образованием & 3,94 & 3,51 \\
\hline Своим материальным положением & 2,79 & 2,85 \\
\hline Отношениями с близкими и друзьями & 4,52 & 4,19 \\
\hline Отношениями с коллегами & 4,34 & 3,90 \\
\hline Экологической ситуацией & 2,56 & 2,56 \\
\hline
\end{tabular}

Таблица 3

Социальные ожидания молодежи Свердловской и Волгоградской областей (в процентах)

\begin{tabular}{|l|c|c|c|}
\hline \multirow{2}{*}{$\begin{array}{c}\text { Как вы считаете, изменится ли ситуация в на- } \\
\text { шем обществе в ближайшие 3 года? }\end{array}$} & $\begin{array}{c}\text { Свердловская } \\
\text { область }\end{array}$ & $\begin{array}{c}\text { Волгоградская } \\
\text { область }\end{array}$ & ИТОГО: \\
\hline Нет, ничего не изменится & 57,6 & 46,4 & 53,6 \\
\hline Да, изменится в худшую сторону & 24,3 & 25,4 & 24,7 \\
\hline Да, изменится в лучшую сторону & 18,1 & 28,1 & 21,7 \\
\hline ИТОГО: & 100,0 & 100,0 & 100,0 \\
\hline
\end{tabular}




\section{СОЦИОЛОГИЯ И СОЦИАЛЬНЫЕ ТЕХНОЛОГИИ}

вая, что в большинстве своем молодые люди недовольны текущим положением дел в стране, а также неудовлетворены важнейшими параметрами своей индивидуальной траектории, можно сделать вывод: мнение, что ничего существенно не изменится, отражает скорее негативный сценарий социального будущего молодежи - «сейчас все не очень хорошо, в ближайшее время останется также плохо».

Каких именно негативных и позитивных событий ожидает молодежь в сценарии развития ближайшего будущего? Респондентам было предложено оценить вероятность наступления различных событий в жизни общества в баллах от 1 до 5 (табл. 4).

Предлагаемые к оценке события мы разделили на две группы. В первую из них вошли события, формирующие позитивный сценарий будущего: успешные экономические и социальные реформы, принятие законопроектов и государственных программ, способствующих развитию деловой активности, предпринимательской и других инициатив, увеличение информационной открытости, прозрачности в обществе, переход от сырьевой экономики к развитию наукоемких отрас- лей и инноваций. Вторая группа событий образует, напротив, негативный сценарий: увеличение внешнеполитической напряженности, конфликтов с другими странами, рост цен, инфляция, снижение жизненного уровня, дальнейшее укрепление государственной власти, властной вертикали, принятие законопроектов и решений, влекущих за собой рост бюрократизации, формализма, политические беспорядки, протесты, увеличение напряженности внутри страны, экологические аварии, способствующие ухудшению состояния окружающей среды.

Ответы респондентов указывают на то, что волгоградская молодежь в большей мере склонна ожидать позитивных перемен от будущего, в то время как свердловская настроена сравнительно скептично. Среди молодежи Волгоградской области более высокие оценки получили события, образующие позитивный сценарий будущего, тогда как среди молодежи Свердловской области, напротив, негативный.

В ответах волгоградской молодежи прослеживается некоторая парадоксальность оценок настоящего и будущего. Можно сказать, что молодые люди этого региона пока

Таблица 4

Оценка вероятности наступления различных событий в стране в ближайшие 5 лет (5 баллов - вероятность наступления события очень высока, 1 балл - вероятность наступления события очень низкая), средние баллы

\begin{tabular}{|l|c|c|}
\hline \multicolumn{1}{|c|}{$\begin{array}{l}\text { Оцените вероятность наступления следующих событий в нашей } \\
\text { стране ближайшие 5 лет: }\end{array}$} & $\begin{array}{c}|c| \\
\text { Регион } \\
\text { область }\end{array}$ & $\begin{array}{c}\text { Волгоградская } \\
\text { область }\end{array}$ \\
\hline Успешные экономические и социальные реформы & 2,17 & 2,51 \\
\hline $\begin{array}{l}\text { Принятие законопроектов и государственных программ, } \\
\text { способствующих развитию деловой активности, предпри- } \\
\text { нимательской и других инициатив }\end{array}$ & 2,45 & 2,75 \\
\hline $\begin{array}{l}\text { Переход от сырьевой экономики к развитию наукоемких } \\
\text { отраслей и инноваций }\end{array}$ & 2,46 & 2,54 \\
\hline $\begin{array}{l}\text { Увеличение информационной открытости, прозрачности в } \\
\text { обществе }\end{array}$ & 2,19 & 2,50 \\
\hline Укрепление государственной власти, властной вертикали & 3,52 & 3,15 \\
\hline $\begin{array}{l}\text { Экологические аварии, способствующие ухудшению со- } \\
\text { стояния окружающей среды }\end{array}$ & 3,18 & 2,96 \\
\hline $\begin{array}{l}\text { Политические беспорядки, протесты, увеличение напря- } \\
\text { женности внутри страны }\end{array}$ & 3,23 & 2,95 \\
\hline $\begin{array}{l}\text { Принятие законопроектов и решений, влекущих за собой } \\
\text { рост бюрократизации, формализма }\end{array}$ & 3,58 & 3,11 \\
\hline $\begin{array}{l}\text { Увеличение внешнеполитической напряженности, кон- } \\
\text { фликтов с другими странами }\end{array}$ & 3,73 & 3,41 \\
\hline Рост цен, инфляция, снижение жизненного уровня & 4,24 & 3,72 \\
\hline
\end{tabular}


готовы выдать кредит доверия власти: при негативной оценке ситуации они ожидают или, скорее, надеются на благоприятные изменения в ближайшем будущем. Почему же молодежь Волгограда выдает этот кредит доверия на позитивные изменения в будущем, при такой же скорее негативной оценке социального самочувствия, как и у свердловской молодежи?

Возможно, дело в различных ориентирах и представлении о том, какое нам общество нужно? Мы провели сравнение социального идеала, базирующегося на определенных ценностных основаниях, разделяемых молодыми свердловчанами и волгоградцами.

Безусловно, существуют общие моменты в конструировании социального идеала. Среди важнейших составляющих портрета желаемого социального будущего у молодежи обоих регионов - высокий уровень жизни, ориентация на развитие высоких технологий, равенство и справедливость, при этом эффективная рыночная экономика (табл. 5). Толерантность и гуманизм как ценностные ориентиры развития общества практически не входят в их образ социального будущего.

Далее рассмотрим различия. У волгоградской молодежи образ желаемого будущего сильнее смещен в сторону паттерналистских ценностей: сильная государственная власть, общество равенства и справед- ливости, с которым считаются другие страны. Это перекликается с некоторыми социальными ожиданиями волгоградской молодежи - достаточно вероятным опрошенные считают дальнейшее укрепление властной вертикали.

Ожидания же свердловской молодежи заметнее расходятся с ее общественным идеалом - молодые люди надеются на высокий уровень жизни и развитие высоких технологий, при этом сильнее всего опасаются роста цен, инфляции и снижения жизненного уровня. Рассогласование идеалов и ожиданий порождает критичность и даже негативизм в оценке как настоящего положения дел, так и будущего сценария социума, и чревато пассивностью либо активизацией радикализма и протестных настроений среди молодежи. Заметим, что, говоря о сравнительно позитивных социальных ожиданиях волгоградской молодежи, мы имеем в виду несколько более оптимистичный настрой по сравнению с молодежью Свердловской области. Однако, характеризуя настроения волгоградской молодежи сами по себе, становится очевидным, что существенная часть молодых людей придерживается пессимистических установок относительно возможного социального будущего, следовательно, в случае молодежи Волгоградской области, мы тоже можем фик-

Таблица 5

Идеал общественного развития молодежи Свердловской и Волгоградской областей (в процентах) *

\begin{tabular}{|l|c|c|}
\hline \multirow{2}{*}{$\begin{array}{c}\text { Существует множество точек зрения на идеал } \\
\text { общественного развития, какие из них разделяете лично Вы? }\end{array}$} & $\begin{array}{c}\text { Свердловская } \\
\text { область }\end{array}$ & $\begin{array}{c}\text { Волгоградская } \\
\text { область }\end{array}$ \\
\hline Общество с сильной государственной властью & 21,1 & 28,6 \\
\hline Общество, где высоко ценят традиции предков & 21,1 & 15,2 \\
\hline $\begin{array}{l}\text { Общество, ориентированное на развитие высоких тех- } \\
\text { нологий }\end{array}$ & 46,4 & 37,9 \\
\hline Общество равенства и справедливости & 39,7 & 43,8 \\
\hline Толерантное общество, терпимое к меньшинствам & 7,2 & 12,9 \\
\hline Гуманистическое общество & 9,2 & 9,8 \\
\hline Общество эффективной рыночной экономики & 37,7 & 39,3 \\
\hline Общество с высоким уровнем жизни & 69,5 & 54,9 \\
\hline Общество, с которым считаются другие страны & 16,6 & 20,5 \\
\hline ИТОГО: & 268,5 & 262,9 \\
\hline
\end{tabular}

\footnotetext{
* Сумма ответов превышает 100 \%, поскольку каждый респондент мог выбрать несколько вариантов ответа.
} 
сировать несоответствие социальных ожиданий общественному идеалу.

Заключение. Резюмируя результаты исследования образа социального будущего молодежи индустриальных регионов, можем заключить следующее.

Текущее состояние дел в различных общественных сферах (политике, экономике, социальной сфере и в культурной жизни общества) не удовлетворяет молодежь обоих исследуемых регионов. Однако параметры удовлетворенности своей индивидуальной траекторией (образованием, работой, состоянием здоровья, отношениями с друзьями и коллегами) несколько выше у молодежи Свердловской области, более благополучной в социально-экономическом плане, нежели Волгоградская область. При этом перспективы изменений в ближайшем будущем волгоградская молодежь оценивает более оптимистично, чем уральцы.

Молодежь Волгоградской области выше оценивает вероятность наступления событий, образующих позитивный сценарий будущего (в том числе успешные экономические и социальные реформы, увеличение информационной открытости, прозрачности в обществе, переход от сырьевой экономики к развитию наукоемких отраслей и инноваций), тогда как молодежь Свердловской области, напротив, более высоко оценивает вероятность наступления негативных событий: увеличения внешнеполитической напряженности, роста цен, инфляции, снижения жизненного уровня и т. д.

Таким образом, прослеживается некоторая парадоксальность оценок настоящего и будущего в ответах волгоградской молодежи: при достаточно негативной оценке ситуации (практически такой же критической, как и у молодежи Свердловской области) молодые люди в большей степени ожидают благоприятных изменений в ближайшем будущем.

Это, на наш взгляд, объясняется некоторым различием ценностных ориентиров, на которых строится образ желаемого социального будущего. У волгоградской молодежи образ желаемого будущего сильнее смещен в сторону паттерналистских ценностей, что отчасти совпадает с социальными ожиданиями, в частности, молодые люди с большой вероятностью ожидают укрепления властной вертикали в ближайшем будущем, усиления государственной власти. Ожидания же свердловской молодежи в большей мере расходятся с ее общественным идеалом - молодые люди желают видеть повышение уровня жизни и развитие высоких технологий, при этом ожидают роста цен, инфляцию и снижение жизненного уровня.

Выявленная нами в результате исследования негативная тенденция дисбаланса между общественным идеалом и социальными ожиданиями молодежи индустриальных регионов, во-первых, не может не вызывать существенных опасений, поскольку рассогласование идеалов и ожиданий порождает критичность и даже негативизм в оценках настоящего и будущего общества, чревато активизацией радикализма и протестных настроений среди молодежи, во-вторых, она нуждается в дальнейшем изучении, исследование данной проблематики представляется нам перспективным направлением в области социологии молодежи.

\section{ПРИМЕЧАНИЕ}

${ }^{1}$ Статья подготовлена в рамках проекта «Молодежь индустриальных регионов России: образ социального будущего как фактор развития инновационного потенциала», реализуемого при поддержке Российского Фонда Фундаментальных Исследований - РФФИ (грант № 18-011-00907\18).

\section{СПИСОК ЛИТЕРАТУРЫ}

1. Бодрунов, С. Д. Реиндустриализация: социально-экономические параметры реинтеграции производства, науки и образования / С. Д. Бодрунов // Социологические исследования. - 2016. - № 2. C. 20-28.

2. Бочарова, Е. Е. Конструирование образа будущего учащейся молодежью как аспект их социального самоопределения / Е. Е. Бочарова // Известия Саратовского университета. Сер. Философия, психология, педагогика. - 2010. - Т. 10, вып. 3. - С. 68-73.

3. Гаврилюк, В. В. Роль образа будущего в выборе жизненных стратегий современной российской молодежи / В. В. Гаврилюк, Л. Л. Мехришвили // Исторические, философские, политические и юридические науки, культурология и ис- 
кусствоведение. Вопросы теории и практики. 2015. - № 7 (57), ч. II. - С. 52-55.

4. Дулина, Н. В. Между заторможенным ростом и модернизацией регионов. Южный федеральный округ / Н. В. Дулина, Е. В. Каргаполова // Социологические исследования. - 2015. - № 3.C. 22-29.

5. Ромашкина, Г. Ф. Процессы модернизации в регионах Уральского федерального округа / Г. Ф. Ромашкина // Социологические исследования. - 2015. - № 1. - С. 19-26.

6. Студент 1995-2016 гг:: динамика социокультурного развития студенчества Среднего Урала / Л. Н. Банникова [и др.] ; под общ. ред. Ю. Р. Вишневского. - Екатеринбург : УрФУ. - 2017. - 904 с.

7. Cundiff, P. R. Great Expectations Unmet: The Impact of Adolescent Educational Expectations on Deviant Coping During the Transition to Adulthood / P. R. Cundiff// Sociological inquiry. -2017.-Vol. 87 (3). P. 449-471.

8. Sabates, R. Ambition Gone Awry: The LongTerm Socioeconomic Consequences of Misaligned and Uncertain Ambitions in Adolescence / R. Sabates, A. L. Harris, J. Staff// Social science quarterly. -2011.Vol. 92 (4).-P.959-977.

9. Scales, P. C. Youth Developmental Assets in Global Perspective: Results from International Adaptations of the Developmental Assets Profile / P. C. Scales // Child indicators research (Special issue). - 2011. - Vol. 4 (4). - P. 619-645.

10. Van Mol, C. Migration aspirations of European youth in times of crisis / C. Van Mol // Journal of youth studies. - 2016. - Vol. 19 (10). - P. 1303-1320.

\section{REFERENCES}

1. Bodrunov S.D. Reindustrializatsiya: sotsialnoekonomicheskie parametry reintegratsii proizvodstva, nauki i obrazovaniya [Re-industrialization: SocioEconomic Parameters of Reintegrating Production, Science and Education]. Sotsiologicheskie issledovaniya, 2016, no. 2, pp. 20-28.

2. Bocharova E.E. Konstruirovanie obraza budushchego uchashcheysya molodezhyu kak aspekt ikh sotsialnogo samoopredeleniya [Designing of an Image of the Future of Young Students as an Aspect of Their Social Self-Determination]. Izvestiya
Saratovskogo universiteta. Ser. Filosofiya, psikhologiya, pedagogika [Proceedings of the Saratov University. Philosophy. Psychology. Pedagogy], 2010, vol. 10, no. 3, pp. 68-73.

3. Gavrilyuk V.V., Mekhrishvili L.L. Rol obraza budushchego v vybore zhiznennykh strategiy sovremennoy rossiyskoy molodezhi [Role of Image of the Future in Choice of Life Strategies of Modern Russian Youth]. Istoricheskie, filosofskie, politicheskie $i$ yuridicheskie nauki, kulturologiya $i$ iskusstvovedenie. Voprosy teorii i praktiki [Historical, Philosophical, Political and Legal Sciences, Culturology and Art History. Questions of Theory and Practice], 2015, vol. 7 (57), no. II, pp. 52-55.

4. Dulina N.V., Kargapolova E.V. Mezhdu zatormozhennym rostom i modernizatsiey regionov. Yuzhnyy federalnyy okrug [Between Decelerated Growth and Regional Modernization: The Southern Federal District]. Sotsiologicheskie issledovaniya, 2015, no. 3, pp. 22-29.

5. Romashkina G.F. Protsessy modernizatsii v regionakh Uralskogo federalnogo okruga [Modernization Processes in the Regions of the Urals Federal District]. Sotsiologicheskie issledovaniya, 2015, no. 1, pp. 19-26.

6. Vishnevskiy Yu.R., ed. Student 19952016 gg.: dinamika sotsiokulturnogo razvitiya studenchestva Srednego Urala [Student 1995-2016: Dynamics of Social and Cultural Development of Students of the Middle Urals]. Ekaterinburg, UrFU Publ., 2017. 904 p.

7. Cundiff P.R. Great Expectations Unmet: The Impact of Adolescent Educational Expectations on Deviant Coping During the Transition to Adulthood. Sociological inquiry, 2017, vol. 87 (3), pp. 449-471.

8. Sabates R., Harris A.L., Staff J. Ambition Gone Awry: The Long-Term Socioeconomic Consequences of Misaligned and Uncertain Ambitions in Adolescence. Social science quarterly, 2011, vol. 92 (4), pp. 959-977

9. Scales P.C. Youth Developmental Assets in Global Perspective: Results from International Adaptations of the Developmental Assets Profile. Child indicators research (Special issue), 2011, vol. 4(4), pp. 619-645.

10. Van Mol C. Migration aspirations of European youth in times of crisis. Journal of youth studies, 2016, vol. 19 (10), pp. 1303-1320. 


\section{Information about the Authors}

Yana V. Didkovskaya, Doctor of Sciences (Sociology), Associate Professor, Professor of Department of Sociology and Technology of the State and Municipal Administration, Ural Federal University, Mira St., 19, 620002 Ekaterinburg, Russian Federation, diyana@yandex.ru.

Nadezda V. Dulina, Doctor of Sciences (Sociology), Professor, Department of Sociology, Volgograd State University, Prosp. Universitetsky, 100, 400062 Volgograd, Russian Federation, nv-dulina@volsu.ru.

Dmitriy V. Trynov, Senior Lecturer of Department of Sociology and Technology of State and Municipal Administration, Ural Federal University, Mira St., 19, 620002 Ekaterinburg, Russian Federation, dmitrynov@inbox.ru.

\section{Информация об авторах}

Яна Викторовна Дидковская, доктор социологических наук, доцент, профессор кафедры социологии и технологий государственного и муниципального управления, Уральский федеральный университет, ул. Мира, 19, 620002 г. Екатеринбург, Российская Федерация, diyana@yandex.ru.

Надежда Васильевна Дулина, доктор социологических наук, профессор кафедры социологии, Волгоградский государственный университет, просп. Университетский, 100, 400062 г. Волгоград, Российская Федерация, nv-dulina@volsu.ru.

Дмитрий Валерьевич Трынов, старший преподаватель кафедры социологии и технологий государственного и муниципального управления, Уральский федеральный университет, ул. Мира, 19, 620002 г. Екатеринбург, Российская Федерация, dmitrynov@inbox.ru. 